Practicing Desire 



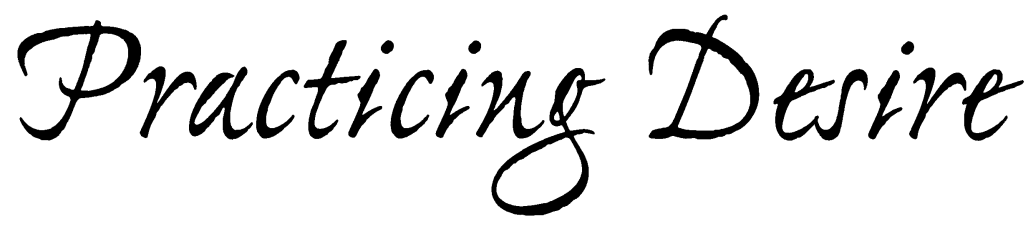

Homosexual Sex in the Era of AIDS

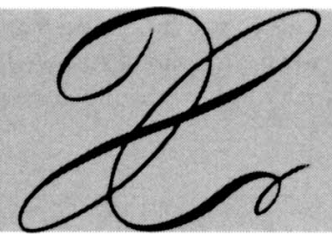

Gary W. Dowsett

Stanford University Press, Stanford, California

I996 


\section{Stanford University Press}

Stanford, California

C 1996 by the Board of Trustees of the

Leland Stanford Junior University

Printed in the United States of America

CIP data are at the end of the book

Stanford University Press publications are distributed exclusively by Stanford University Press within the United States, Canada, Mexico, and Central America; they are distributed exclusively by

Cambridge University Press throughout the rest of the world. 
This study is dedicated to the late Peter Charlton - actor, writer, gay man, model PLWHA, and friend-and his muse, the greatest diva of them all. 
